\title{
Indigenous health: radical hope or groundhog day?
}

\section{Professor Ernest Hunter explains why learning from the past and investing strategically will have the best chance of success}

$\mathrm{n}$ his book Radical hope: education and equality in Australia, Aboriginal lawyer, academic and land rights activist Noel Pearson contends:

Governments and their bureaucracies are informed by everything other than memory of what was done five years ago, ten years ago and eighteen years ago. Politics are remembered, policies are not. ${ }^{1}$

It also includes his 2004 Judith Wright Memorial Lecture, in which, reflecting on the political forces necessary to drive national change in Indigenous affairs, he notes:

it will take a prime minister in the mould of Tony Abbott to lead the nation to settle the "unfinished business" between settler Australians and the other people who are members of this nation: the Indigenous people. ${ }^{1}$

A decade on, Tony Abbott, as Prime Minister, delivered the Closing the Gap report. ${ }^{2}$ Having identified that his government's new engagements will involve centralising responsibility for Commonwealth-funded programs in the Department of the Prime Minister and Cabinet, setting up the Prime Minister's Indigenous Advisory Council and fostering linkages between bureaucrats, business and Indigenous leaders, he details mixed outcomes across four key areas - health, education, employment and safe communities. The outcomes were consistent with the Closing the Gap Clearinghouse report released a year earlier, ${ }^{3}$ which identified key high-level principles and practices characterising programs that worked: flexibility to meet local needs and contexts; community involvement and engagement; building trust and relationships; a well trained and resourced workforce; and continuity and coordination. Themes associated with less successful initiatives included: programs implemented in isolation; short-term funding and high staff turnover; lack of cultural safety; and inflexible program delivery. Similar issues emerged in a recent review of early childhood parenting, education and health intervention programs. ${ }^{4}$

Clinicians working in remote Australia will not be surprised. There have been health gains, but they are uneven: remote Indigenous Australia is clearly behind. Furthermore, it can be argued that for some conditions and in some areas the situation is worse despite significant clinical investments. For instance, when I began work as a psychiatrist in Cape York and the Torres Strait over 20 years ago, there were no mental health or substance misuse services. Now there are well over 100 workers across Queensland Health, Education Queensland, the Royal Flying Doctor Service, Medicare Locals, community-controlled services and Commonwealth-funded programs, plus contracted private clinicians. This does not include the dozens of residents trained variously in community and personal wellbeing, empowerment, mental health literacy, suicide prevention and more. Sadly, the situation in terms of mental illness is worse, probably reflecting both contemporary social contexts and delayed effects of neurodevelopmental adversity. 5,6

doi: 10.5694/mjal4.00557 Our understanding of the developmental determinants of chronic disease in Indigenous Australians has been evolving for more than half a century ${ }^{7}$ and there is accumulating evidence on childhood social factors increasing the risk of adultonset mental disorders. For example, bereavement stress in mothers during the first years of life (particularly after suicide in the family) increases the risk of affective psychosis. ${ }^{8}$ Research on such topics involves controlling for potential confounders. In the real world of remote Indigenous communities, many children are exposed to serial adversity: pregnancies affected by high levels of stress; poor nutrition and inadequate antenatal care; prematurity; infant environmental instability and attachment difficulties; hospitalisation and other forms of separation from caregivers; bereavement stress; exposure to violence; early-onset substance misuse; and more. We can only presume that the consequences of such risk amplification will be substantial.

In 2006, soon after Pearson commended him, Tony Abbott called for a new form of "paternalism" that would be "based on competence rather than race" to address unrelenting Indigenous health problems associated with failed past policies such as self-determination. ${ }^{9}$ Now, he holds the reins. But whatever happens, the economic agenda will weigh heavily; Indigenous Australians will not be quarantined from budget cuts, changes to Medicare and welfare entitlements, privatisation, and the continuing feud between federal and state governments over health funding. In Queensland, public sector services (particularly population health and health promotion) sustained dramatic losses in the 2012-13 financial year that will be most consequential for remote Indigenous communities. Career public sector employees are giving way to locums, casual workers, agency nurses and project workers funded by non-government organisations. While this may bring new ideas, it 
risks losing domain knowledge and incremental improvement based on practice-based evidence. ${ }^{10}$

While there is no doubt that greater economic selfreliance will be critical to Indigenous futures, I believe that there is complacency regarding the flow-on effects of the contraction of federal and state public sectors for Indigenous health in remote Australia. Indeed, to support self-reliance in the long term, it is critical that we increase and sustain strategic investment in public health and clinical programs for pregnancy and early childhood to optimise neurodevelopmental potential. Is it "radical hope" to suppose that the new paternalism and new engagements will deliver? Or, as Pearson suggests in his chapter on cycles of policy reinvention in Indigenous affairs, will it be groundhog day?

Competing interests: No relevant disclosures.

Provenance: Commissioned; externally peer reviewed.

1 Pearson N. Radical hope: education and equality in Australia. Melbourne: Black Inc, 2011.

2 Australian Government. Closing the Gap: Prime Minister's report. Canberra: Commonwealth of Australia, 2014. http://www.dpmc.gov.au/ publications/docs/closing_the_gap_2014.pdf (accessed Apr 2014).
3 Closing the Gap Clearinghouse. What works to overcome Indigenous disadvantage: key learnings and gaps in the evidence 2011-2012. Canberra: Australian Institute of Health and Welfare; Melbourne: Australian Institute of Family Studies, 2013. http://www.aihw.gov.au/uploadedFiles/ ClosingTheGap/Content/Publications/2013/15161.pdf (accessed Apr 2014).

4 Bowes J, Grace R; Closing the Gap Clearinghouse. Review of early childhood parenting, education and health intervention programs for Indigenous children and families in Australia. Issues Paper No. 8. Canberra: Australian Institute of Health and Welfare; Melbourne: Australian Institute of Family Studies, 2014. http://www.aihw.gov.au/uploadedFiles/ ClosingTheGap/Content/Our_publications/2014/ctgc-ip08.pdf (accessed Apr 2014).

5 Hunter E. Indicators of psychoses or psychoses as indicators: the relationship between Indigenous social disadvantage and serious mental illness. Australas Psychiatry 2013; 21: 22-26.

6 Hunter EM, Gynther BD, Anderson CJ, et al. Psychosis in Indigenous populations of Cape York and the Torres Strait. Med J Aust 2012; 196 : 133-135.

7 Hunter E. Hearts and minds: evolving understandings of chronic cardiovascular disease in Aboriginal and Torres Strait Islander populations. Australian Aboriginal Studies 2010; (1): 74-91.

8 Abel KM, Heuvelman HP, Jörgensen L, et al. Severe bereavement stress during the prenatal and childhood periods and risk of psychosis in later life: population based cohort study. BMJ 2014; 348: f7679.

9 Govt paternalism push meets Indigenous outrage. PM [radio program]. Australian Broadcasting Corporation, 2006; 21 Jun.

10 Hunter E, Onnis LA, Santhanam-Martin R, et al. Beasts of burden or organised cooperation: the story of a mental health team in remote, Indigenous Australia. Australas Psychiatry 2013; 21: 572-577.
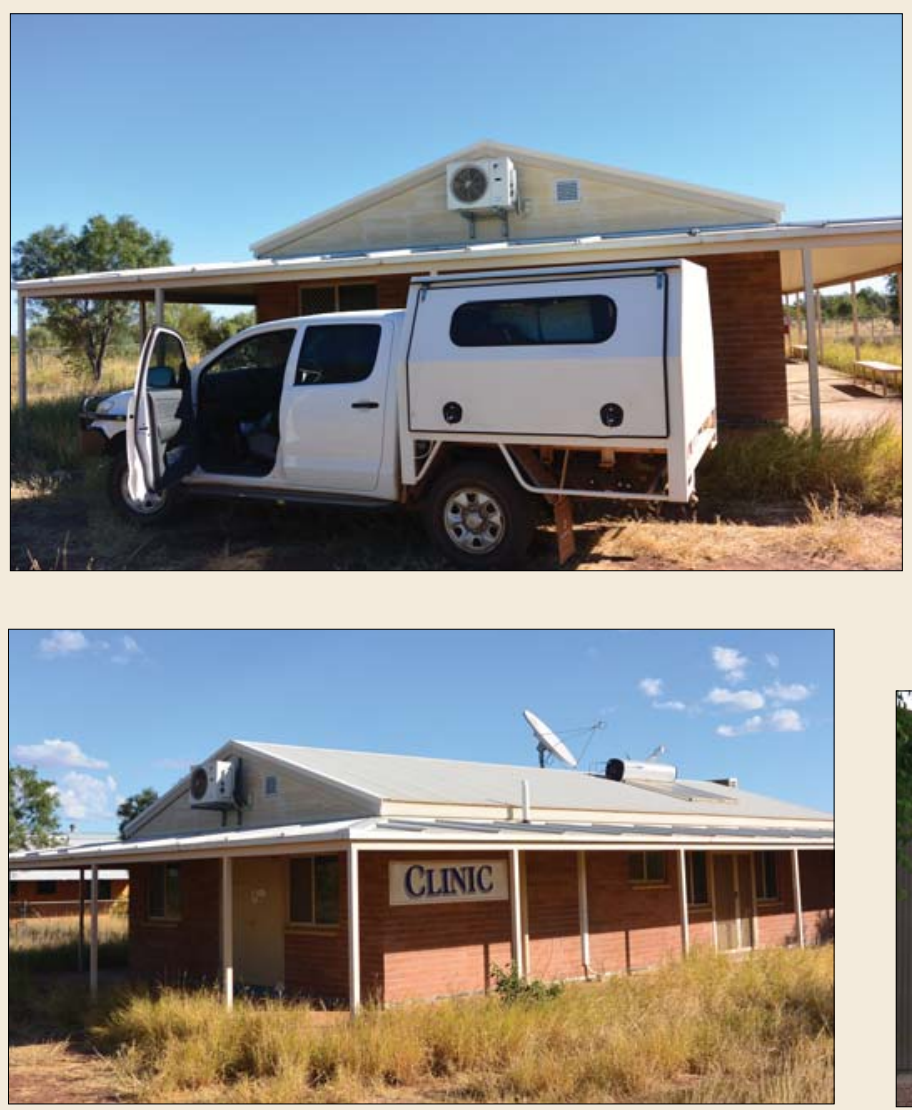

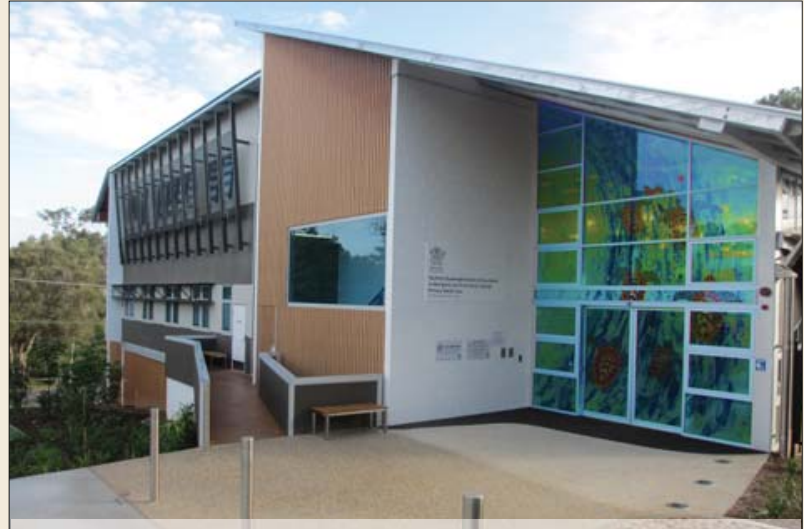

Courtesy Southern Qld Centre of Excellence for Aboriginal and Torres Strait Islander Primary Health Care, page 623

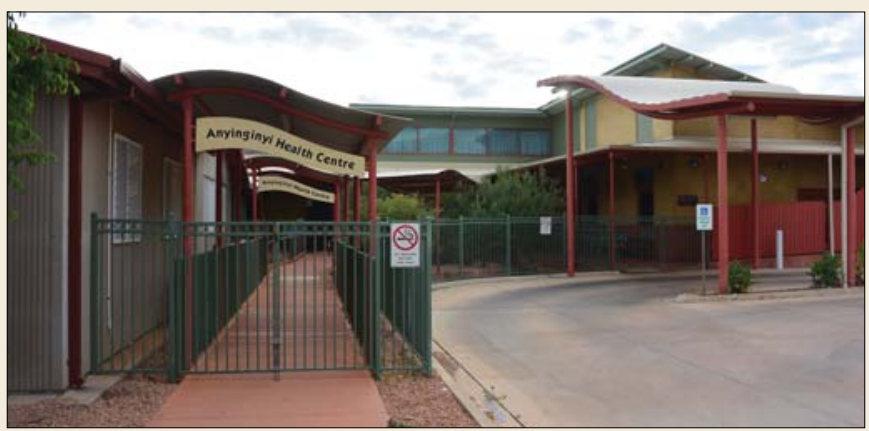

